\title{
Ibadan school library digital resource system: the long-awaited solution for Nigerian schools
}

\author{
Kolawole Akinjide Aramide ${ }^{1}$ and Taiwo Elizabeth Ogunjobi ${ }^{2}$ \\ ${ }^{1}$ Department of School Library and Media Technology, University of Ibadan, Nigeria \\ ${ }^{2}$ Department of Library, Information and Documentation, Cocoa Research Institutes of Nigeria, Idi \\ Ayunre, Ibadan, Nigeria. And Visiting Scholar, Department of School Library and Media Technology, \\ University of Ibadan, Nigeria.
}

\begin{abstract}
This paper discussed the development of Ibadan School Library Digital Resource System for schools in Nigeria. The paper extensively discussed the evolution of library software from CDS/ISIS, TINLIB, GLAS, X-LIB and ALICE. The paper also considered strengths and weaknesses of library software developments in Nigerian over the years with specific emphasis on school libraries. The paper further examined the development of Ibadan school library digital resource system which is considered to be adequate and suitable library system for Nigerian schools. The three main divisions of the Ibadan School Library Digital Resources software were critically examined such as Integrated Library Management Software, Learning management system and electronic resources. The failure of libraries software in Nigeria was critically examined which include lack of skilled manpower, funding, poor maintenance of equipment and irregular power supply. The paper finally recommended the adoption of Ibadan School Library Digital Resource System as suitable and adequate System for elementary and high schools in meeting the information needs and improving the academic performance of pupils and students in Nigerian Schools.
\end{abstract}

\section{Introduction}

The challenges of finding a suitable and adequate Integrated Library Management System (ILMS) for the Nigerian local context has been a major concern to all stakeholders in librarianship profession over the years. This is because, most of the library software that has been adopted in the past have always failed at one point or another. Therefore, the need to search for ILMS that is sustainable within the Nigerian local context has been at the forefront of discourse in recent years. Because the deployment and utilisation of ILMS is the way to

* Corresponding author: kolaakinjide@gmail.com 
go in this current dispensation, it is expedient that stakeholders in library and Information service delivery find a solution to this problem of finding suitable ILMS that can help them in attaining the library's objectives. The adoption and utilisation of ILMS is becoming an indispensable activity in the $21^{\text {st }}$ century libraries and Information service delivery (1). The major advantage of adoption and utilisation of ILMS is that it has the capacity to enhance ease of access, visibility and effective use of information resources therein. Meanwhile, empirical findings and observation over the years have also revealed that the Nigerian Schools are always left behind in the search for suitable ILMS for their operations as all efforts are usually concentrated on tertiary institutions. However, the school library is very important to successful achievement of the educational goals of a nation.

A school library is a school's physical and digital learning space where reading, inquiry, research, thinking, imagination, and creativity are central to students' information-toknowledge journey and to their personal, social, and cultural growth. This physical and digital place is known by several terms such as school media centre, centre for documentation and information, library resource centre, library learning commons (2). A school library operates within a school as a teaching and learning centre that provides an active instructional program integrated into curriculum content, with emphasis on resource-based capabilities, abilities and dispositions related to seeking, accessing, and evaluating resources in a variety of formats, including people and cultural artefacts as sources. These capabilities also include using information technology tools to seek out, access, and evaluate resources, and the development of digital and print-based literacies. Many studies have been conducted on adoption of ILMS in Nigeria but none have surveyed the development of school library digital resources system for schools in Nigeria, hence the need for this study.

\section{Evolution of ILMS for Libraries in Nigeria}

Efforts on deployment of library software in Nigerian libraries started in the mid-1990s at the Kenneth Dike Library, University of Ibadan, Nigeria. Nigeria used the opportunity presented by the World Bank and organised and executed by the National Universities Commission (NUC) in the 1994-1995 session. The NUC donated computers to university libraries in Nigeria and encouraged them to acquire TINLIB library software for their computerisation projects. Unfortunately, the software was abandoned due to lack of adequate maintenance support and technical guidance (3). Other University libraries have made attempts to use other software including GLAS, X-LIB, VIRTUA and ALICE without meaningful success. Library automation systems today require considerable programming skills together with an extensive knowledge of functional needs and standards. Most automation efforts in Nigerian academic libraries have failed due to lack of feasibility studies, hence the search for appropriate software to meet the local needs of libraries continues. Software selection is not an easy task for libraries. This has given rise to high software turnover in Nigerian library automation projects (4). The selection of appropriate software is an important step in library automation. In the present scenario, a number of library management software packages are being used in Nigerian University Libraries such as KOHA, X - LIB, SLAM, DSpace, TINLIB, VTLS, ALICE for Windows, VIRTUA, GLAS, E-Lib and CD-ISIS. A review of the literature on library automation in Nigerian academic libraries reveals that most university libraries depend on free and donated software. For example, the University of Ibadan Library started with CDS/ISIS that was developed and distributed freely by UNESCO in 1993. In 1994, the library migrated to TINLIB which was introduced by the World Bank Project in 1994-1995. By 2004, University of Ibadan later 
changed to ALICE for window which also developed problems that made the University to opt for in-house software as an alternative.

The reason for the multitude usages of TINLIB was because the NUC made the software available for universities under the world bank intervention loan package to Nigerian Universities (3). This computer software did not carry the universities very far. Consequently, this led to discontinuation of TINLIB by Ibadan University to the need for change in the operating system from DOS to Windows (5). DOS-based software lack flexibility and were incapable of performing the advanced functions required for delivering smooth library services. By 2004, Ibadan acquired ALICE for Windows. Although the software was Windows-based, it did not meet the needs because it was not MARC 21-compliant and, as a result, it had no interface for sharing resources. Inadequate provision of funds for university libraries and lack of maintenance support for the software were rated as the greatest problems associated with software use in libraries in Nigeria (6).

\subsection{Justification for Appropriate software for School Libraries}

It was discovered that all other softwares that have been developed and used by Nigeria libraries could not properly fit into our local context, that is the major reason why foreign software failed. Also, most of these softwares were developed by programmers without the input of librarians who are the end users. For software to perform satisfactorily, it must have librarians' input. In addition, most of these softwares are open source and this is not perfect for school system. Moreover, hardware equipment to support these software's are expensive, this makes it difficult for elementary and high schools in Nigeria to adopt them. Hence there is need to develop a software that can take care of afore-mentioned weaknesses for schools in Nigeria. This led to the development of Ibadan school library digital resource.

\section{Ibadan School Library Digital Resource Centre}

Abadina Media Resource Centre now Department of School Library and Media Technology was established in 1974 at the University of Ibadan. University of Ibadan is the only University that has department of school library in the whole of West Africa. The specific objectives of the department include the development of appropriate reading skills among Nigeria youths particularly among primary and secondary school pupils, development of multimedia collections that will support production of children's learning resources to enhance qualitative education in schools in Nigeria, organise periodically, conferences and workshops that are germane to keeping school library media personnel abreast of developments in the field of school librarianship and effective use of learning resources as well as provide consultancy services to government, their development partners, and other organisations in relation to management of school library/media resource centres as may be requested from time to time (7).

Ibadan school library digital resources system (ISLDRS) for schools at the Department of school library and media technology is a 3-in-1, high-capacity electronic library server system that provides complete digital library facilities with virtual access and on-premises hosting to several educational web portals, sites, and resources for nursery, primary and secondary schools with little running cost. It was developed with the following objectives:

- To promote digital library and web electronic learning in elementary and secondary schools with or without internet connectivity; 
- To provide students and teachers with digital resources that will encourage more interactive digital learning in schools;

- To provide a platform for educational electronic contents creators to directly deploy their content materials to schools without online web hosting;

- To encourage students' interest in the educational aspect of the internet in contrast to the social aspect;

- To provide internet electronic library services in schools at no or optional periodic running costs.

- The system provides fast and free access to several educational web portals with hundreds of thousands of interactive audio-visual resources and millions of learning materials, including interactive digital textbooks and Storybooks. The system provides a fully functional and user-friendly e-Learning Management portal that can help teachers/tutors in administering e-teaching to students.

- The interactive and audio-visual resources provided with the system will help schools to have more academically engaged students and have their academic performances improved.

- The fear of pupils or students being exposed to inappropriate online content will be removed.

- The server machine can serve as internet service provision for educational purposes in schools at no periodic subscription cost.

The birth of Ibadan School Library Digital Resources System (ISLDRS) started in 2015 with the open discussion with a technical partner called Polawa e-resources. A proposal was requested from them. In 2016, a demonstration of the digital resource system developed by Polawa was tested but it lacked Integrated Library Management System (ILMS). In 2017, Polawa came for second demonstration with the inclusion of ILMS while the third and final demonstration was done in 2018. The Department certified the system as good for the school settings in Nigeria and request was made to the University of Ibadan administration in 2019 for the acquisition of the system and was approved. Finally, in June 2020, Ibadan school library digital resources System was deployed along with a 3-day for all the staff of the department training. Presently, the system is deployed in offline mode while the Department is working towards the online and mobile App versions of the system. The system has 3 major interfaces which comprises, learning management system (LMS) called my teachers platform, integrated library management system (ILMS) for librarians and users' platform.

\subsection{Learning Management System (LMS)}

Learning management system is designed for interaction between teachers and students just like google classroom and electronic resources components. Learning Management System section of the ISLDRS is purely icon-based e-learning system that provides necessary modules for e-tutoring, e-testing, e-assignment and collaborative platform for teachers to share their ideas and knowledge as contributions to the system. 
International Conference of Information Communication Technologies enhanced Social Sciences and Humanities 2021 - ICTeSSH 2021

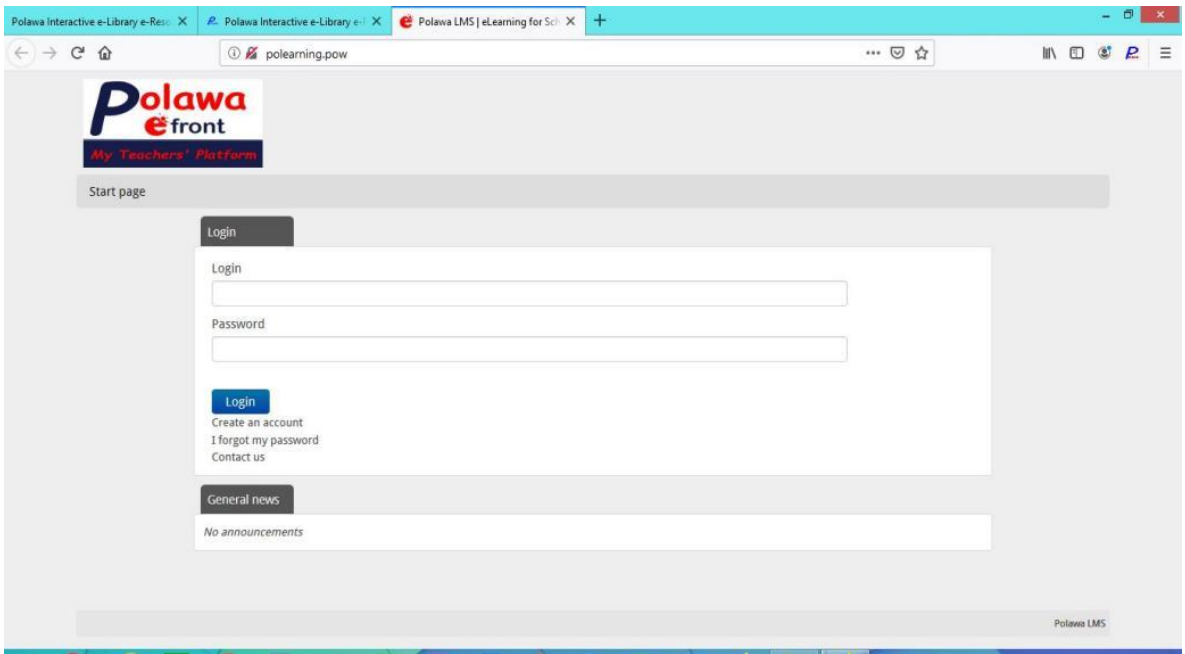

Fig. 1. Learning management system (LMS)

\subsection{Integrated Library Management Software (ILMS)}

Integrated Library Management System (ILMS) is meant for librarians. It is called Polawa elibrary for librarians. It is the librarian platform portal. It has a single module that enables the school librarian performs all library housekeeping operations. The librarian platform portal provides schools' librarians a system to automate and manage schools' library digitally carry out e-librarian functions such as acquisition, cataloging, circulation, serials control, reporting, membership management and other settings.

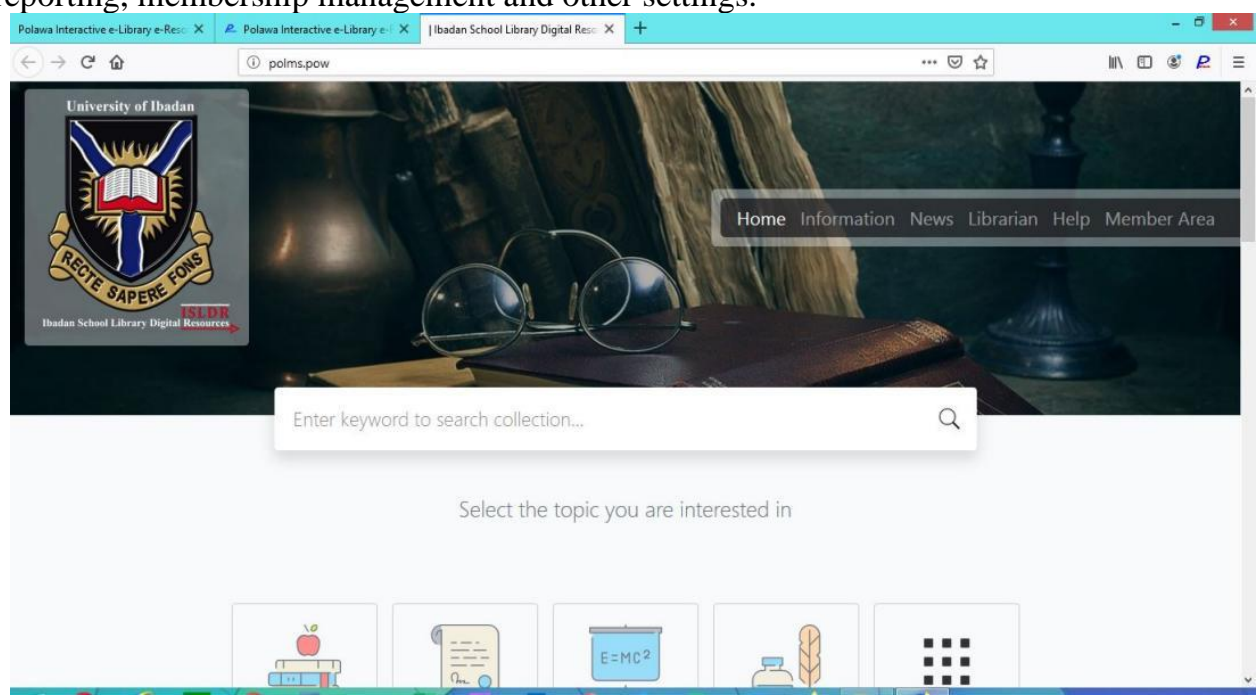

Fig. 2. Integrated Library Management System 
International Conference of Information Communication Technologies enhanced Social Sciences and Humanities 2021 - ICTeSSH 2021

\subsection{Library Users Modules}

There are nine modules for users in the ISLDRS. The nine modules for users are Polawa interactive e-library, Polawa e-library books, PHET interactive simulation, E-Learning for kids or founding dreams, Boundless resources, Wikipedia for schools, Ka- Lite academic contents, Khan Academy contents and GCF- Learn free.org. Polawa interactive e-library (audio-visual and interactive educational aid) has thirteen subjects on arts, biology, brain teasers, chemistry, computer studies, English language, general science, geography, language studies, mathematics, music, physics and social studies. This platform also has catalogue of educational games, videos, simulations for students in kindergarten up to secondary schools.

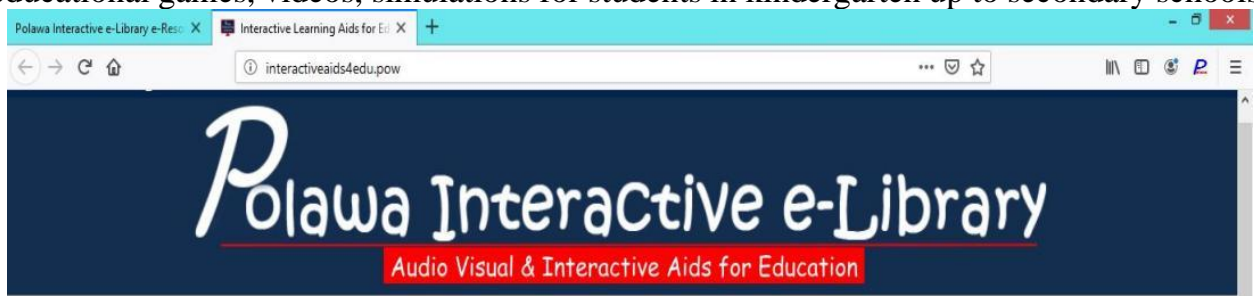

You are welcome to Polawa Interactive e-Library Portal!

This Digital Library is a catalogue of Educational Games, Videos and Simulations for Students in Kindergarten up to Secondary School.

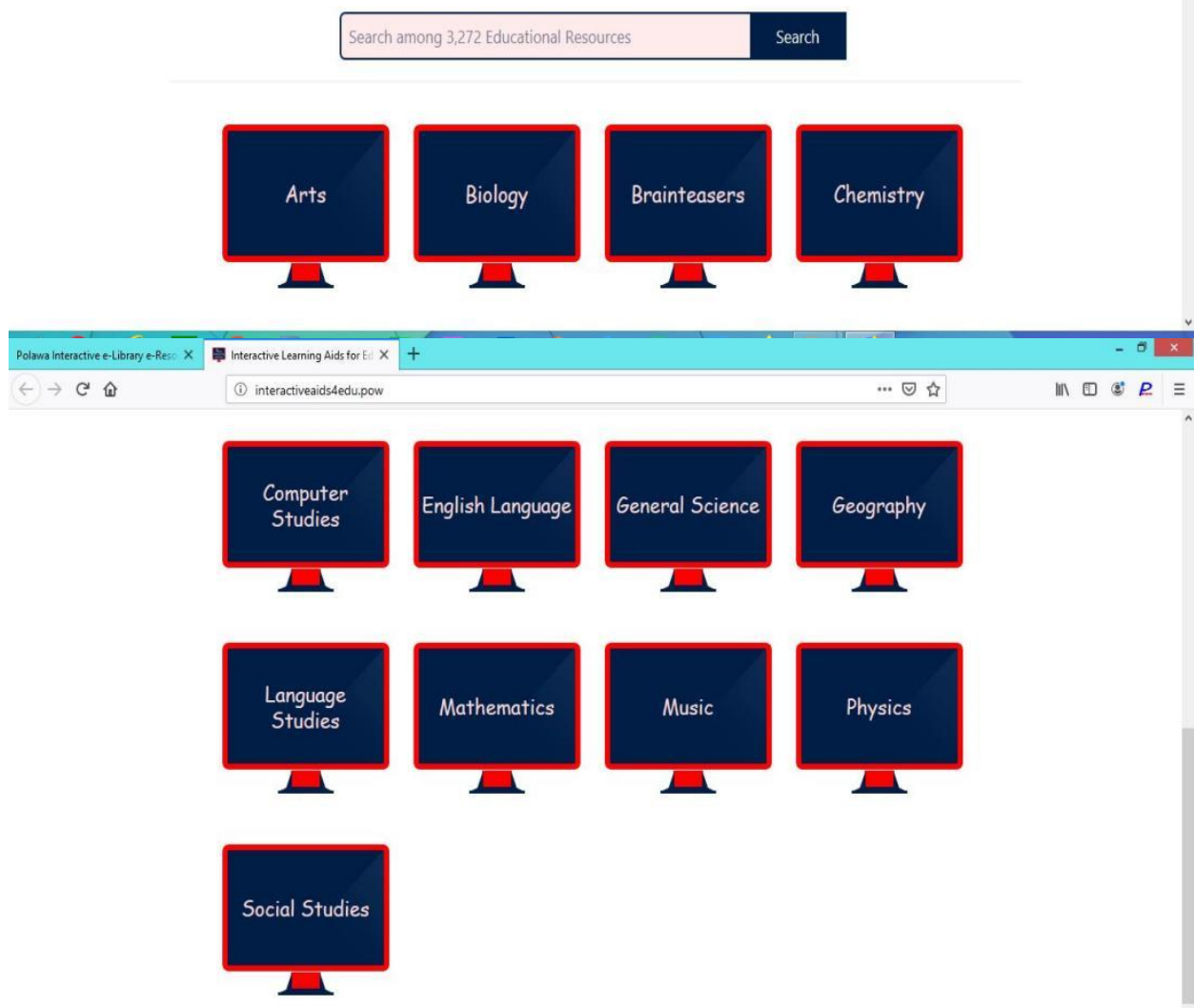

Fig. 3. POLAWA Interactive E-library 
International Conference of Information Communication Technologies enhanced Social Sciences and Humanities 2021 - ICTeSSH 2021

\subsubsection{Polawa e-library books}

This consists of books of all subjects with different topics. It is a section of the ISLDRS which is developed to promote digital reading among primary and secondary school students. It has 530 short story books and tales with 149 text books for primary students, 252 story books and 469 text books for college students. Primary story books contain fewer word stories (177), Few words stories (109), many words stories (232) and religious stories (14).

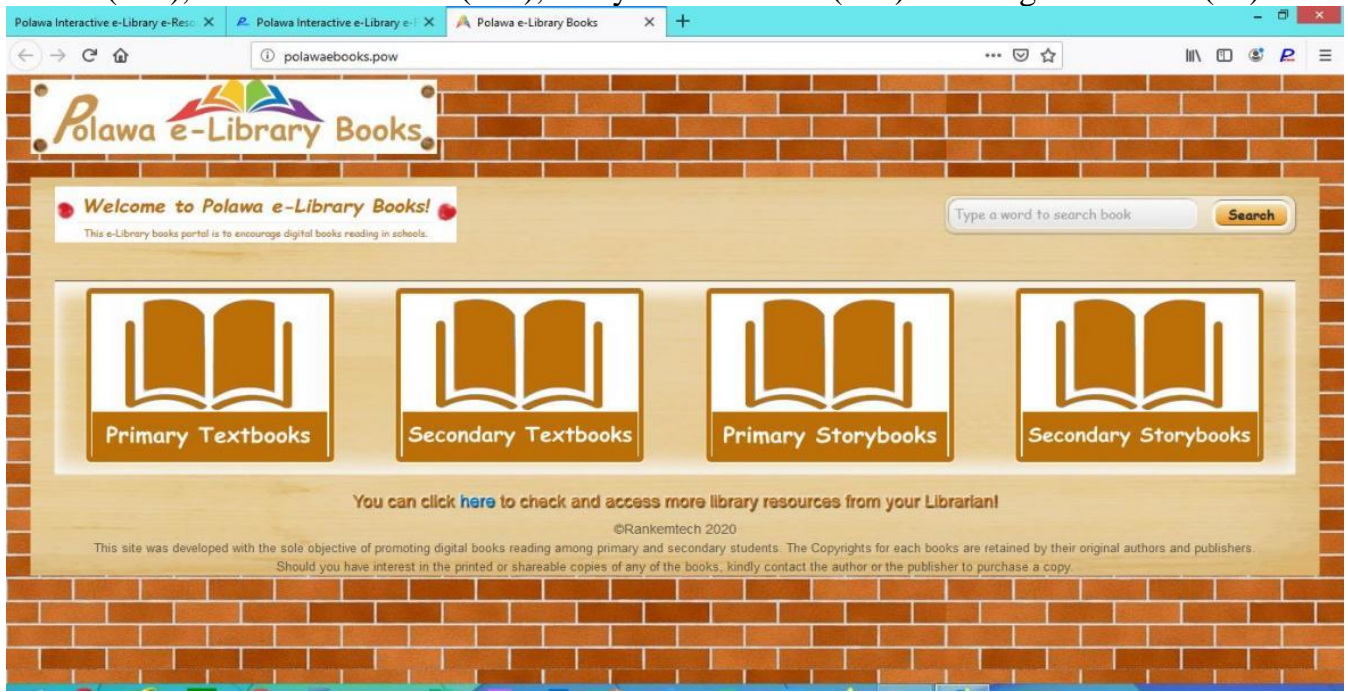

Fig. 4. POLAWA E-library books

\subsubsection{E-Learning for Kids or Founding dreams}

E-Learning for kids or founding dreams provides children around the world with high quality digital primary education for free. It contains 361 subjects on pure and applied sciences

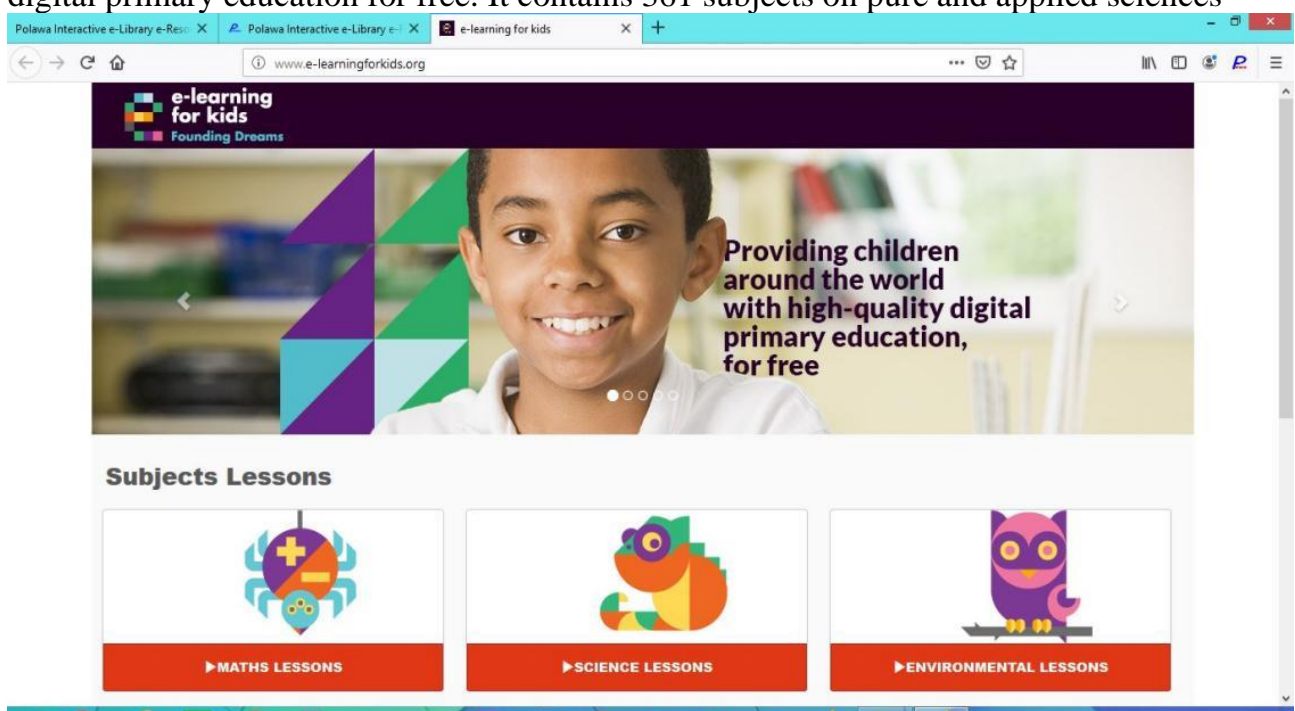

Fig. 5. E -learning for kids 
International Conference of Information Communication Technologies enhanced Social Sciences and Humanities 2021 - ICTeSSH 2021

\subsubsection{Boundless Resources}

Boundless resources contain high quality contents for teaching needs on arts, sciences, management, finance, marketing and political science. Is for science and mathematics and over 360 million simulations delivered.

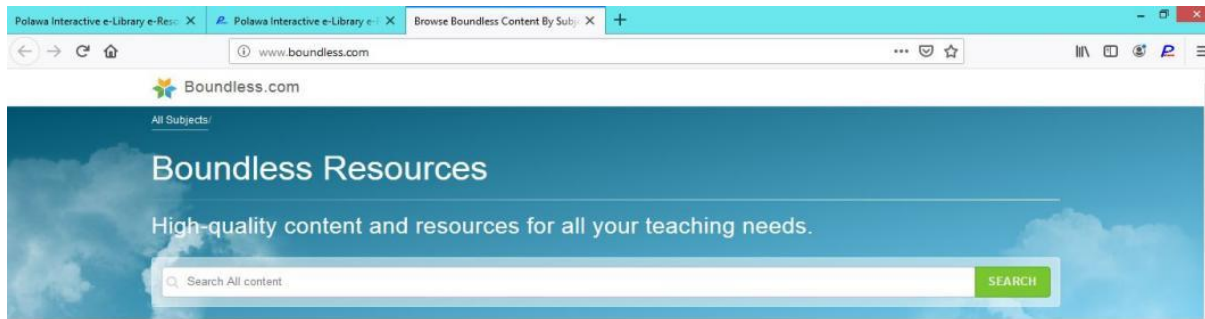

Fig. 6. Boundless Resources

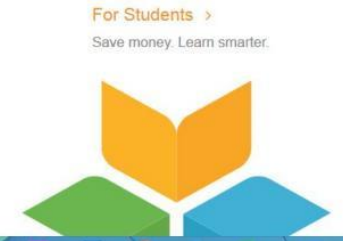

\subsubsection{PHET interactive simulation}

This is for science and mathematics and over 360 million simulations delivered. PHET simulations are based on extensive educational research and engage students through an intuitive, game-like environment where students learn through explorative and discovery. It contains chemistry, physics, mathematics, biology, health sciences, android app and wise award winner.

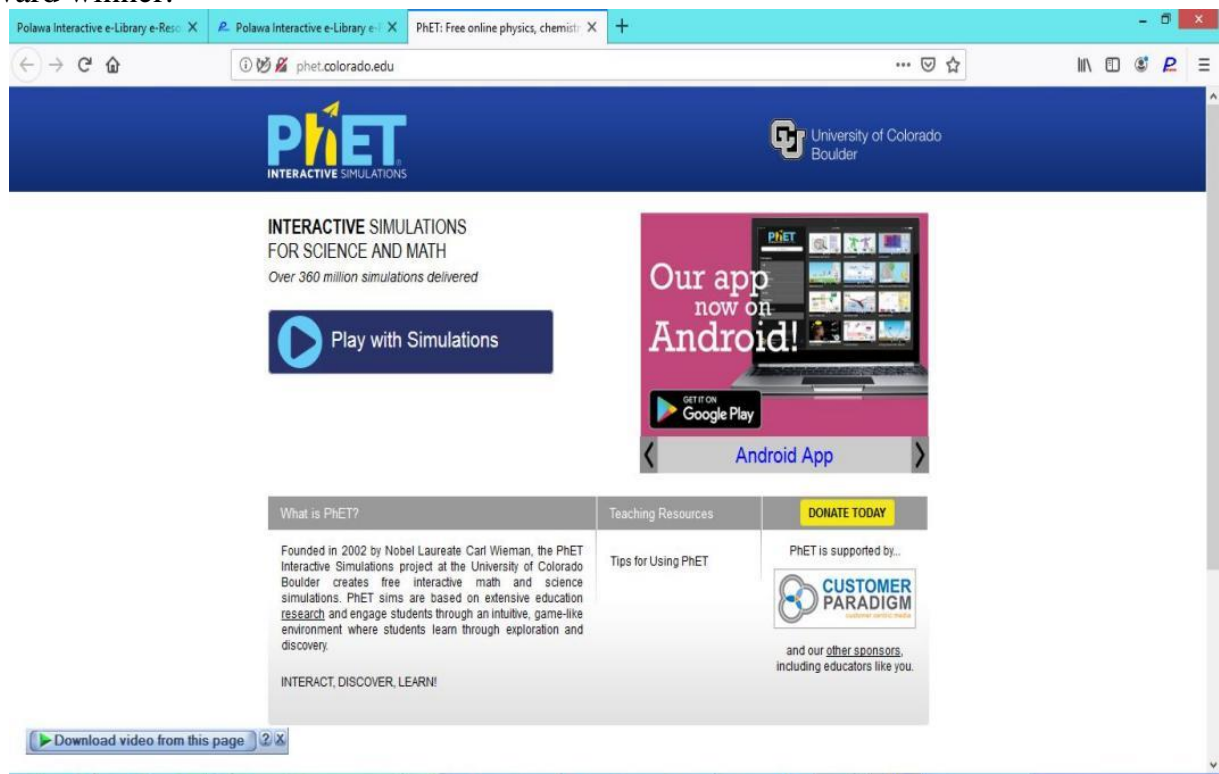

Fig. 7. PHET Interactive Simulation 
International Conference of Information Communication Technologies enhanced Social Sciences and Humanities 2021 - ICTeSSH 2021

\subsubsection{Wikipedia for schools}

It can be used by school children around the world. It contains six thousand $(6,000)$ articles, twenty-six million $(26,000000)$ words, fifty thousand $(50,000)$ Images.

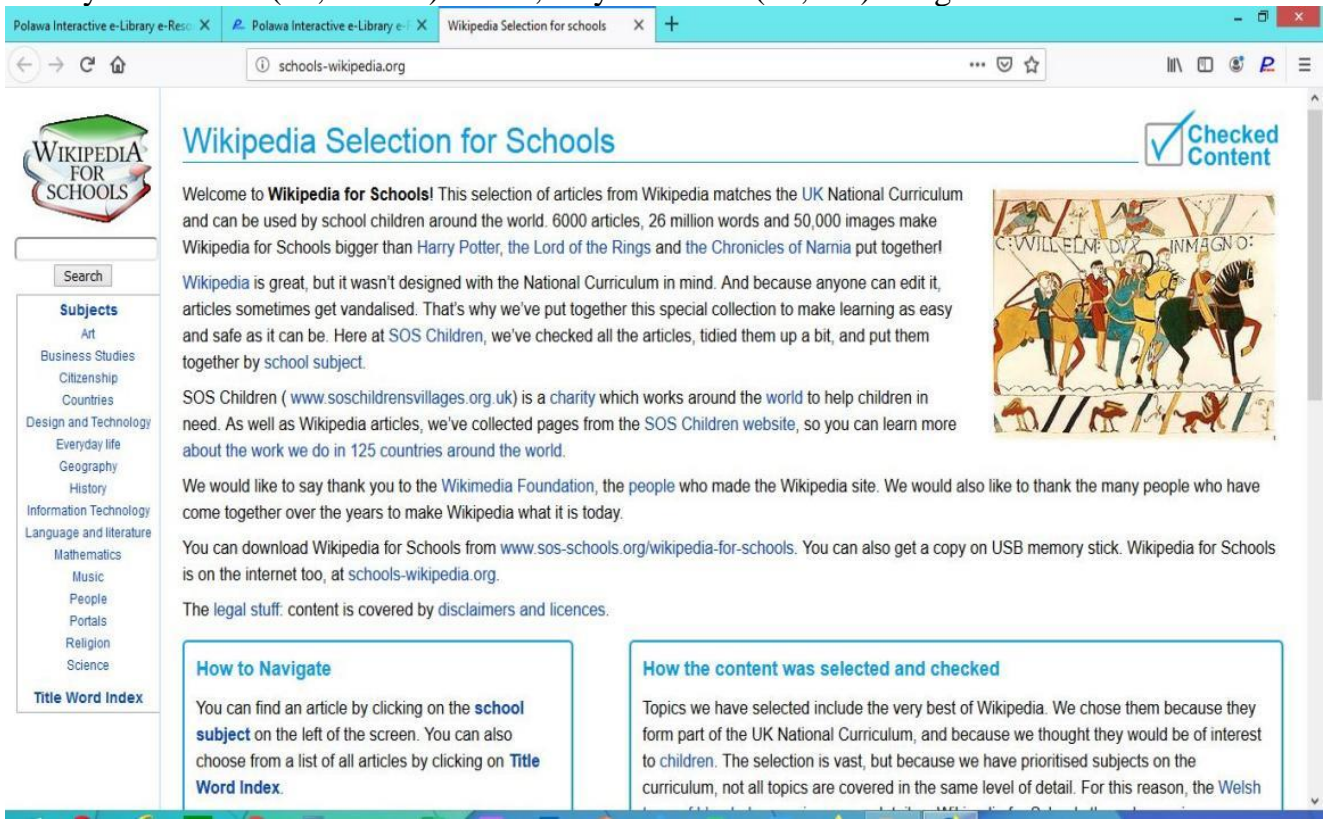

Fig. 8. Wikipedia for schools

\subsubsection{Khan Academy contents}

It contains videos for all subjects in mathematics and sciences while Ka-Lite Academic contents is a light weight web server. It is for viewing and interacting with core Khan academic contents. It contains videos and exercises without needing an internet connection. It treats science, economics, computing, arts and humanities. It contains Arithmetic and prealgebra (355), Algebra (638), Geometry (180), Trigonometry precalculus (361), calculus (297) Probability and statistics (136) and differential equation (46). It also consists of Biology (72), chemistry (70), Physics (203), osmology and astronomy (86), organic chemistry (221) and health care and medicine (193).

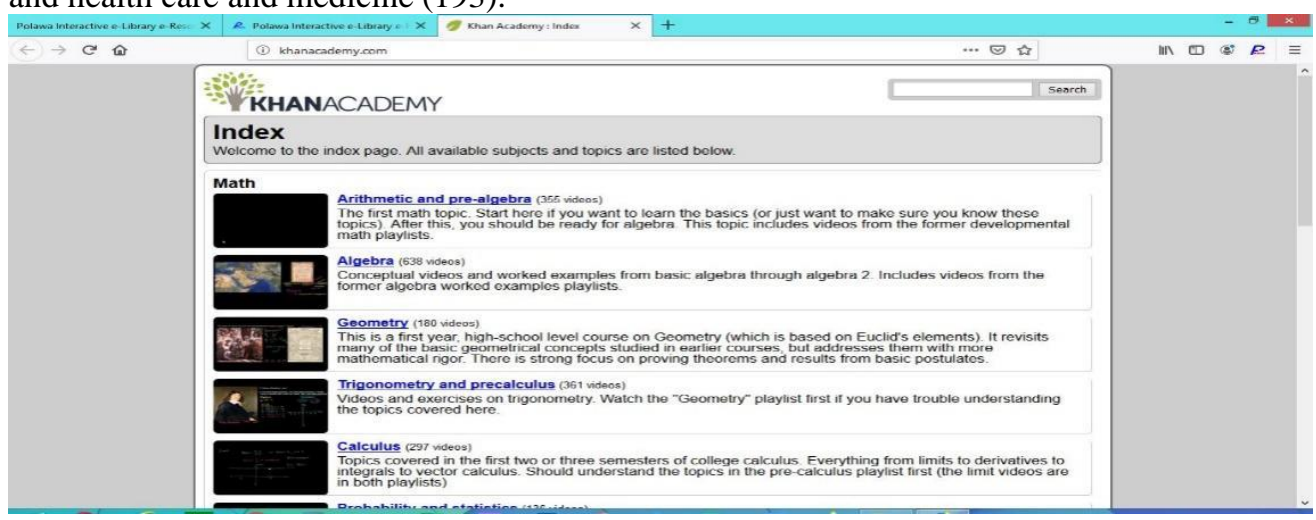

Fig. 9. KHAN Academy 


\subsubsection{GCF- Learn free.org}

It contains one thousand lessons on technology, reading, mathematics, microsoft office, works and careers.

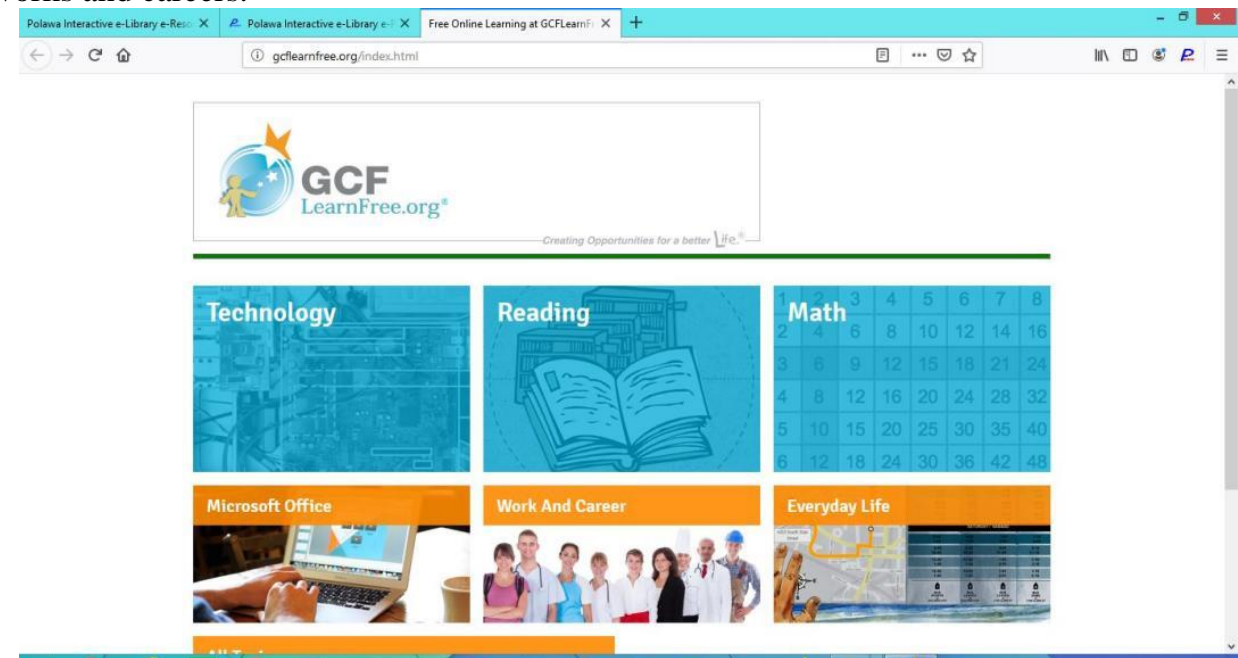

Fig. 10. GCF- Learning free.org

\subsubsection{Ka-Lite Academic contents}

Ka-Lite Academic contents is a free world class educator for anyone anywhere with facilities for viewing and interacting with core Khan academic contents (videos and exercises) without needing an internet connection. It treats mathematics, science and economics. For mathematics, watching videos and practise your skills on almost any maths subjects. For sciences, you learn about all the sciences prom physics, chemistry, biology to cosmology and astronomy.

On economics and finance, micro economics, macroeconomics, finance, accounting and capital market. Art and humanities comprise of beauty, war, religion, society, language. It also gives users opportunity to earn how to code computer programs, how to design algorithms that makes computer more efficient. Ka-lite also contains test preparation on SAT, MCAT, NCLEX-RN, GMAT, CAHSEE, IIT.JEE, among others.

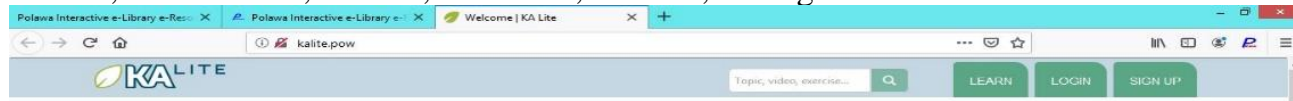

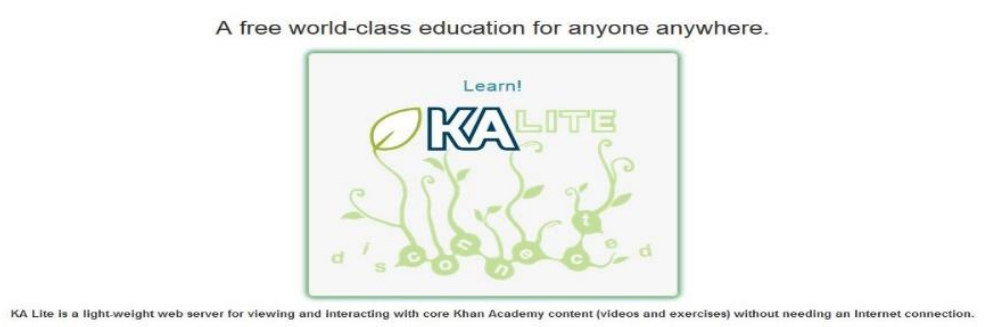

Fig. 11. Ka-Lite Academy content 


\section{Conclusion and Recommendation}

Different types of services are being offered by ISLDRS, hence this makes it suitable and adequate for the Nigerian school settings. It has all the capacity and capability to develop the reading culture of Nigerian child which is fast declining, provides the platform which the Nigerian child are comfortable in relating with being digital natives, remove the boredom associated with the use of physical books among children and ultimately enhance and boost academic performance of children and young adults. It will also improve their digital skills of the students. The ISLDRS also makes the job of the school librarian easy just as it affords the teachers the opportunity of engaging the pupils and students in remote asynchronous mode.

\section{References}

1. Ukpana M.E, Ebong M.D. and Enang U. U. (2018) Journal of Library and Information Sciences, Vol. 6 (1): 37-43.

2. IFLA (2015) IFLA school library guidelines revised edition. Accessed on November 15,2020 from www.ifla.org

3. Bozimo, D. O. (2006). ICT and the Ahmadu Bello University Libraries. Nigerian Libraries: Journal of the Nigerian Library Association, 39(2),1-20.

4. Oketunji, I. (2008), "Choice of library application software and their sustainability: necessary outline", in Current Trends in ICT: Application to Technical Service, NLA Cat \& Class section, Abuja.

5. Ola, O.O. (2010), "Who is a librarian? A biannual publication of the Kenneth Dike Library, University of Ibadan", Nigerian Libraries: Journal of the Nigerian Library Association, $\quad 1(1), 23-46$.

6. Imo and Igbo (2011), "The challenges of software use in Nigerian university libraries: review of experiences from 1990-2009", Library Philosophy and Practice, available at: www.webpagesuidaho.edu/_mbolin/imo-igbo.pdf. Journal of the Nigerian Library Association, 39 (2). 1-20

7. Aramide K.A. (2020). Gaining the balance for the missing link: training school library media specialists for the Nigerian schools A paper presented at Nigerian Association of Library Information Science Educators (NALISE) Conference, November 25. 